\title{
Laryngeal Behaviour and Fluency-inducing Therapy
}

\author{
Marlene Behrmann MA (Speech Path.) (Witwatersrand) \\ Department of Speech Pathology and Audiology, \\ University of the Witwatersrand, Johannesburg
}

\begin{abstract}
The laryngeal behaviour of an adult stutterer was assessed pre- and post-therapy intervention. Intervention comprised a fluency based program directed to the modification of phonatory behaviour and rate reduction. Electrolaryngographic tracings, as well as severity and frequency ratings, were obtained pre- and post-intervention. Results revealed a marked change in all measurements post-intervention, indicating the effectiveness of therapy. The efficacy of the electrolaryngograph as a measurement tool was illustrated and the results are considered in the light of the current literature on phonatory disturbance in stuttering.
\end{abstract}

\section{OPSOMMING}

Die laringeale gedrag van 'n volwasse hakkelaar is pre-en post-terapeutiese ingryping ondersoek. Ingryping het uit 'n vlotheidsgebaseerde program, gerig op die wysiging van fonatoriese gedrag en vermindering van spoed, bestaan. Elektrolaringeografiese optekeninge asook beoordelings t.o.v. die graad en frekwensie van die hakkelgedrag, is voor en na terapeutiese ingryping verkry. Die doeltreffendheid van terapie is bewys deurdat ' $n$ opvallende verskil t.o.v. alle post-ingrypingsmetings gemerk is. Die effektiwiteit van die elektrolaringeograaf as meetinstrument is aangetoon en die resultate is teen die agtergrond van die huidige literatuur i.v. m. fonatoriese afwyking in hakkel bespreek.

The concept of an organic etiology of stuttering is not a novel one, stuttering having been ascribed to, among others, neurological causes, auditory perception problems and biochemical factors (Van Riper 1978). Recently, numerous allusions to abnormal laryngeal functioning of stutterers have been made, but whether this abnormal functioning is due to etiological or symptomatological factors is as yet undetermined and may indeed prove unanswerable. Several writers have stated that the problem resides in the larynx itself whilst others have suggested that an overriding neural component is responsible for the disturbed phonatory behaviour (Conture, McCall and Brewer 1977). The stutterer's inability to initiate phonation and to make vocalization adjustments has been examined (Adams and Reis 1971), as has voice onset time problems (Cross and Luper 1979) and unusual abductory laryngeal behaviour (Schwartz 1974). Perkins (1981) has concluded that there exists a "mistiming and excessive contraction of laryngeal and supraglottal muscles".

One of the difficulties in examining the laryngeal behaviour of stutterers arises from the lack of testing equipment. The development of the electrolaryngograph affords the researcher the opportunity of investigating the phonatory pattern of a speaker in a non-invasive manner (Fourcin and Abberton 1971). This technique which provides a dynamic, instantaneous and simple method for assessing vocal fold contact and for examining the laryngeal behaviour of stutterers, has not been extensively applied to stuttering nor has it been used to evaluate the laryngeal behaviour pre- and postintervention. The laryngographic tracings are obtained by placing two electrodes on either side of the thyroid cartilage. The output is derived from the voltage variations which result in the changing conductance of the vocal fold configurations.

A potential application of the electrolaryngograph is as a means of examining laryngeal functioning following therapy which has been instituted specifically to modify vocal fold movement. One such therapy program, "Stutter Free Speech" (Shames and Florance 1980) is designed to modify the phonatory behaviour of the speaker through continuous phonation. A further purpose of this program is to establish rate control and this dimension together with the emphasis on phonatory adjustments, has currently proved to be the most effective variable handled in treatment (Andrews et al. 1982). The Stutter Free therapy program falls within the 'Speak More Fluently' school of stuttering therapy, as discussed by Gregory (1979). These approaches, also known as the fluency-inducing therapies, advocate the establishment, maintenance and transfer of an entirely new speech pattern. The call for clearer delineation and identification of the factors which contribute to the success or failure of stuttering therapy has been made by Boberg, Howie and Woods (1979) and continued research into the outcome of therapy is necessary both to predict the amount of change and to enhance and modify existing treatment regimes.

\section{METHODOLOGY}

The aim of the current study is to evaluate the change in a stutterer's laryngeal behaviour following a therapy program designed to intervene at the level of phonation. The applicability of the electrolaryngograph as a measurement tool of laryngeal behaviour will also be considered.

A single case study design was selected in accordance with Perkins (1983) proposal that studies "with an $\mathrm{N}$ of l" support the tendency away from hypothetical speculation and provide much nceded empirical evidence.

\section{SUBJECT DESCRIPTION}

The subject, $\mathrm{S}$, was a 31 year old male who had stuttered since early childhood. No family history of stuttering had been reported. $\mathrm{S}$ had received therapy previously but there had been no observable change in his speech pattern. No previous history of laryngeal pathology had been noted. S presented as a Phase IV advanced stutterer, according to Luper and Mulder's (1964) classification system. His speech pattern was characterized by severe blocks and hard contacts, tense repetitions and interjections of phonemic and non-phonemic utterances. Tension loci were identified as the lips, tongue, laryngeal area and abdomen. Secondary behaviours

Die Suid-Afrikaanse Tydskrif vir Kommunikasieafwykings, Vol. 32, 1985 
included eye blinking, head jerks, lip tremor and flaring of the nostrils. Respiratory disturbances were evident in frequent pausing, gasping and speaking on residual air. Fluency facilitating techniques (utilised prior to the implementation of a therapy program) such as whispering, choral speaking and slowed speech produced a decrease in the frequency and severity of stuttering. $S$ obtained a score of 12.9 on the Erikson S24 (1969) scale which suggests that he viewed himself in a positive light prior to intervention.

\section{PRE-INTERVENTION SPEECH ASSESSMENT}

The need for comprehensive assessment pre-intervention has been highlighted by Andrews, Guitar and Howie (1981). A preintervention percentage of syllables stuttered (\%SS) and a mean syllable per minute (SPM) were computed in order to describe the frequency and severity of the stutter pattern. A sample of S's speech was collected including a spontaneous speech sample, a reading sample and a telephone call interchange. These varying conditions were included since Bloodstein (1975) contended that the stutter pattern varies under different circumstances. For the purposes of - this study, stuttering was defined as "any sound or syllable repetition, block, prolongation or effortful emission of a word or syllable" (Ingham, Andrews and Winkler 1972).

The pre-intervention $\%$ SS were $26,5 \%, 18,2 \%$ and $31,4 \%$ for the three samples outlined above. These figures are suggestive of a severe stutter pattern in comparison with previous studies (Goldsmith and Anderson 1984) and support the classification of $S$ as a Phase IV advanced stutterer. The mean SPM counts were 139,5, 132 and 123 for the three samples and are all slow compared with the norm of 196 SPM for normal speaking adult males (Andrews and Ingham 1971), thus confirming the diagnosis of a severe stutter pattern.

The electrolaryngographic examination was conducted using a Uher 4200 report Stereo I.C. Tape Recorder with a M816 directional microphone to record the subject's spoken output while the Mingograf inkjet recorder traced the laryngeal information. The subject was seated in a comfortable position with the microphone at a distance of $30 \mathrm{~mm}$ from the lips. Tracings were made on both a spontaneous speech sample and a reading sample. Owing to practical difficulties the tracings could not be carried out during a telephone conversation. The dimensions for analysing the laryngographic tracings were selected to yield a comprehensive picture of laryngeal functioning. Examples of the pre-intervention tracings are presented in Figures la and $\mathrm{lb}$ which reflect the spontaneous speech and reading samples respectively.

a. Regularity of the wave - this dimension refers to the maintenance of a stable vibratory pattern which is achieved through the laryngeal musculature and through air pressure control. Much variabil-
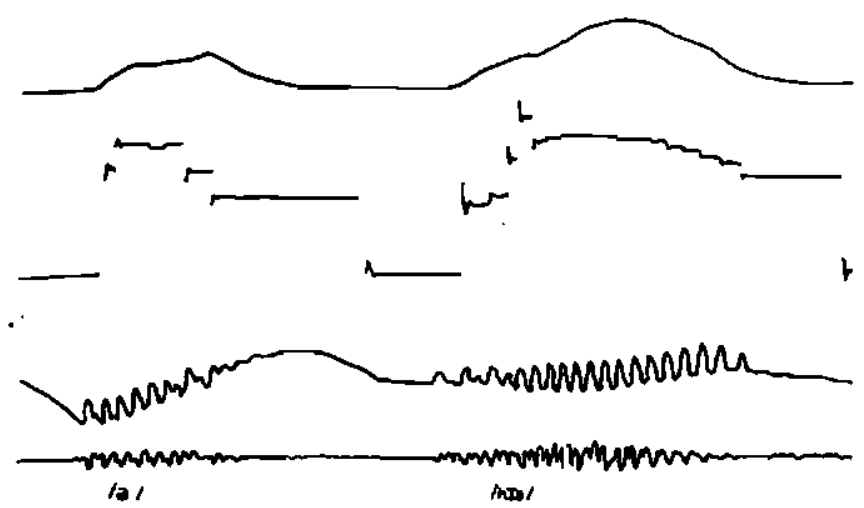

Figure la Examples of pre-intervention spontaneous speech laryngographic tracings

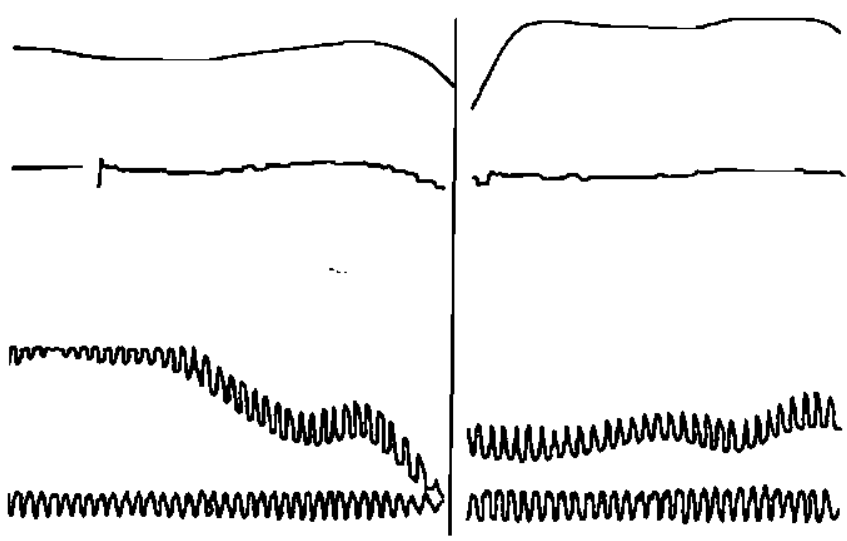

Figure 1b Examples of pre-intervention laryngographic tracings during reading

ity and erratic movement may be observed in Figures la and $\mathrm{lb}$ and these tracings reflect a disturbance in laryngeal functioning and co-ordination as described by Conture et al. (1977). An alternative explanation is that the laryngeal inco-ordination results from an uneven interplay between the agonist and non-agonist laryngeal muscles. These results are supported by studies which have demonstrated abnormal laryngeal functioning in stutterers (Adams and Reis 1971; Schwartz 1974).

b. Shape - the shape of the waveform (Lx) provides a basis for determining the nature of the vocal fold contact and its timing (Anthony 1978). A normal vibratory cycle consists of a rapid closing phase (adduction), represented by a vertical rise, a slower opening phase (abduction) shown as a downward tracing and a period of no contact when the glottis is opening. The pre-intervention spontaneous speech tracing (Fig. la) reflects an erratic pattern of vocal fold movement as noted in the poorly proportioned rise and fall times and the exaggerated gradual decline owing to the failure of the folds to meet along their entire length. The double peak at base provides further evidence for asynchronous vibration.

c. Ease of achieving steady amplitude - this dimension, measured from the first excitation until steady amplitude is achieved, reflects the ease with which a stable vibratory pattern is instituted. An impressionistic overview reveals that steady amplitude is achieved relatively quickly in the pre-intervention tracings, although amplitude variations are noted on the fluent and stuttered phonatory stretches. This pattern is indicative of a difficulty in regulating the vibratory pattern even during the fluent phases of speech.

d. Fx: refers to the fundamental frequency of voicing (Anthony 1978) and the term 'jitter' has been coined to describe the Fx pitch variations. The relative degrees of rise and fall provide crucial information about normal and deviant vibration patterns. Sporadic jitter, especially at the onset of phonation, was evident across all conditions. Almost the entire pre-intervention utterance was characterized by jitter, suggestive of an uneven mode of vocal fold vibration. The increases in Fx reflect the tension of the laryngeal muscles and increased subglottic air pressure.

e. $G x$ : refers to the observation of gross laryngeal adjustments. This dimension is superimposed on the $\mathrm{Lx}$ waveform. Rapid laryngeal adjustments are noted pre-intervention especially on the spontaneous speech sample. This finding, however, must be viewed with caution since the excess $\mathrm{Gx}$ activity may have resulted from the subject's secoridary symptoms such as head jerks (although the subject was requested to remain still during the recordings) and not necessarily from laryngeal activity. In view of this, any judgements on pre-intervention Gx must be reserved. 
In sum, the pre-intervention laryngographic tracings reflect disturbed phonatory patterns as evidenced by, for example, the variable waveform, amplitude variations and irregular shape. These findings suggest a dysfunction at the laryngeal level both during spontaneous speech and during reading. The laryngeal abnormalities noted on the reading tracings are not as marked as those on the spontaneous speech tracings.

\section{THERAPY PROCESS}

An intensive schedule of therapy was undertaken since the subject lived out of town and a limited time period was available. In many instances intensive therapy has been regarded as the ideal form, especially in a fluency based program as the 'new' speech pattern may be acquired in a short period of time. Twenty three hours of therapy were completed in ten days. The first three stages of the Stutter Free program were completed. This involved the establishment of a fluent speech pattern under volitional control as well as self-reinforcement and transfer. It was hoped that an alternative form of laryngeal behaviour would be achieved by this stage and that the remaining two phases of the program (unmonitored speech and follow-up) would be monitored over a long period of time.

A number of modifications were made to the program, devised by Shames and Florance (1980). Delayed auditory feedback was excluded since the subject achieved continuous phonation of his own accord. Syllables per minute were calculated instead of words per minute as words differ in their syllable count and do not facilitate cross-language comparison (Hayhow 1983). Pre-planned contract activities were arranged in a hierarchical manner in accordance with Van Riper's (1978) suggestions.

Post-intervention measurements were taken following the termination of the therapy and compared to the pre-intervention baselines.

\section{POST-INTERVENTION SPEECH ASSESSMENT}

The post-intervention tracings were taken following the identical procedure of the pre-intervention recording. Figures $2 a$ and $2 b$ depict examples of the post-intervention tracings.

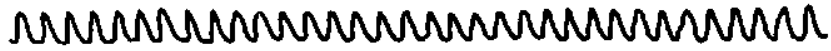

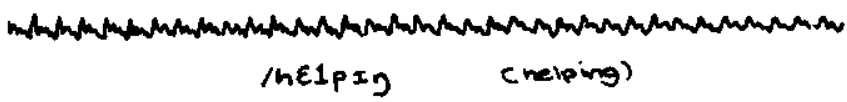

Figure 2a Example of post-intervention spontaneous speech laryngographic tracing

a. Regularity of the wave - the post-intervention tracings reflect a more regular and stable waveform post-intervention than the preintervention tracings. Figures $2 \mathrm{a}$ and $2 \mathrm{~b}$ suggest a controlled vibratory pattern of the vocal folds.

b. Shape - a synchronous, symmetrical mode of vibration is evident from the spontaneous speech and reading post-intervention trac-

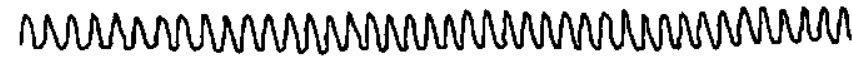

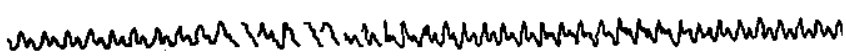

\section{Figure 2b Example of post-intervention laryngographic tracing during reading}

ings. A distinguishing feature of these tracings is the relatively flat base which suggests a long open phase of the vocal folds. Figures $2 \mathrm{a}$ and $2 \mathrm{~b}$ resemble each other closely although the spontaneous speech tracing (Figure 2a) contains more evidence of abnormality than the reading tracing. The reading tracing (Figure $2 b$ ) demonstrates a sharp vertical rise (closure) associated with maximum excitation of the folds followed by a sharp peak or short period of maximum contact. The decline is vertical and the rise and fall times are well proportioned. These results approximate normal laryngeal functioning.

c. Ease of achieving steady amplitude - a change in amplitude control following intervention is observed since no amplitude variations are noted on the post-intervention tracings. The absolute amplitude cycle could not be compared across the pre- and post-intervention tracings since the gain on the laryngograph was turned up on the post-intervention recording and hence any differences may be a result of artifact.

d. $F x$ : the post-intervention tracings depict a stable $F x$ and thus suggest the elimination of the tension of the laryngeal muscles.

e. $G x$ : Post-intervention tracings reveal no Gx activity thus providing further evidence for a change in laryngeal behaviour. Table 1 summarises the overall trends of the laryngographic tracings and allows for comparisons across the pre- and post-intervention conditions.

Table 1 Summary of overall trends of laryngographic analysis pre- and post-intervention

\begin{tabular}{|c|c|c|c|c|}
\hline & \multicolumn{2}{|c|}{$\begin{array}{l}\text { Pre-intervention } \\
\text { Speech Reading }\end{array}$} & \multicolumn{2}{|c|}{$\begin{array}{l}\text { Post-intervention } \\
\text { Speech Reading }\end{array}$} \\
\hline a. regularity of $L x$ wave & +- & +- & + & + \\
\hline b. normal vibratory cycle & - & +- & + & + \\
\hline c. steady amplitude obtained & - & +- & + & + \\
\hline d. Fx jiner & + & - & - & - \\
\hline e. $\mathrm{Gx}$ & + & - & - & - \\
\hline
\end{tabular}

Change across all dimensions is observed except for the Fx jitter and $\mathrm{Gx}$ which remained the same for the pre-intervention spontaneous speech and reading and the post-intervention conditions. Despite this, an alteration of phonation mode is seen in both reading and in spontaneous speech following intervention. The post-intervention tracings approximate normal patterns along all dimensions, apart from the lengthened wave base. This additional feature on the post- 
intervention tracings is not unusual since Metz, Onufrak and Ogburn (1979) observed that post-therapy speech may be fluent despite the addition of certain temporal characteristics. It must be borne in mind that the therapy program was not entirely complete at this stage and thus the timing element was not yet habituated.

It was also interesting to note that the results of the Erickson attitude scale taken after the therapy program showed change as a score of 9.2 was obtained. Hayhow (1983) has proposed that therapy continue until an \$24 score of ten or less (for males) is achieved as was done in the present study.

Of interest, too, is the comparison of the post-intervention frequency and severity ratings with the pre-intervention scores. The postintervention \%SS and SPM are presented in Figure 3 for comparison with the pre-intervention assessment. A post-intervention reduction in \% SS is evident across all conditions and the post-intervention \%SS count falls within the normal limit of $6,5 \%$ SS as specified by Andrews and Ingham (1971). The telephone condition produced the highest \%SS both pre- and post-intervention, a finding which supports the observation of Leith and Timmons (1983) that the telephone is the most difficult situation for stutterers.

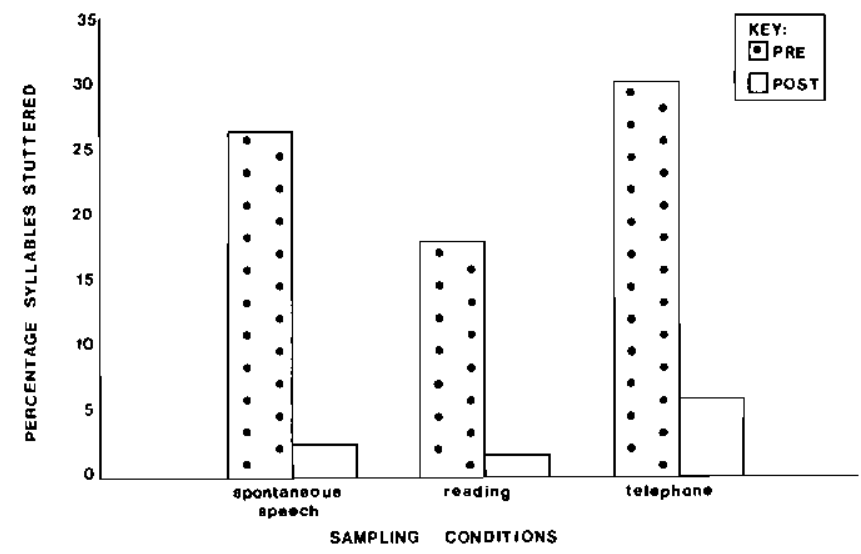

Figure 3 Mean percentage syllables stuttered across all conditions pre- and post-intervention

A minimal increase in SPM was noted from pre- to post-intervention speech sampling (See Figure 4). The post-intervention rate of approximately 140 SPM is slow compared to normals but may be accounted for in terms of the stage of therapy attained i.e. 140 SPM stutter free speech under volitional control.

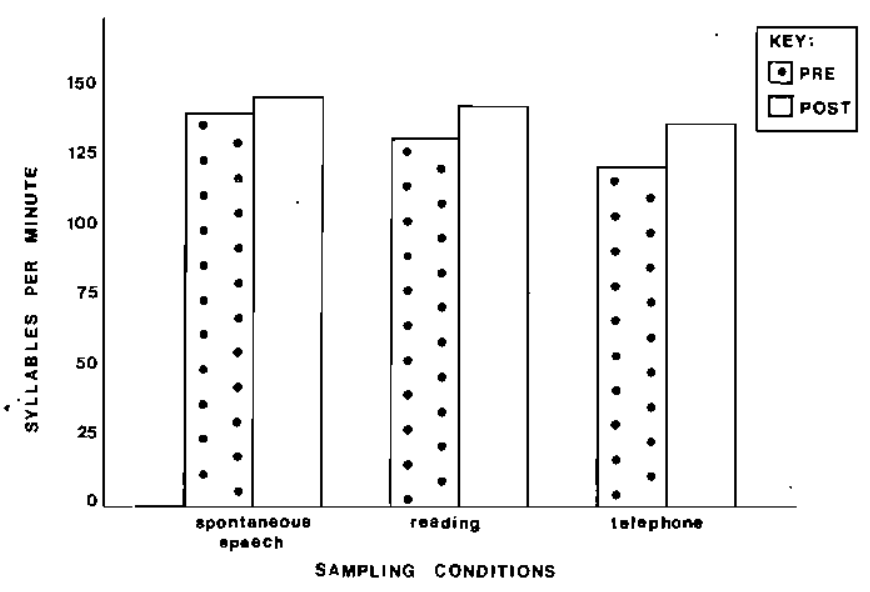

Figure 4 Mean syllables per minute across all conditions pre- and post-intervention.
It is evident from these results that not only did a change in laryngeal patterns occur but a definite alteration of the frequency and severity of stuttering was also noted.

The present findings support the contention that laryngeal disturbances are associated with stuttering (Conture et al. 1977; Wingate 1977) and that modifications in laryngeal behaviours are possible through the implementation of a continuous phonation therapy program. Although it is impossible to determine whether the laryngeal abnormalities are the cause or effect of stuttering, it is interesting to note the relative ease with which the laryngeal dysfunction could be remediated. It may be postulated that in accordance with Schmitt and Cooper (1978), the irregular phonatory behaviour reflects habituated compensatory strategies in response to the dysfluencies and thus the pathology, whether neurological or physiological, does not 'reside' in the vocal folds themselves. This suggestion, however, is speculative and further evidence is indicated.

This case study has highlighted the benefits of a fluency inducing therapy program and has revealed the alteration in the laryngeal behaviour and the change in frequency, severity and rate of the stutter pattern. Furthermore, it illustrates the necessity for in-depth baseline evaluation of the stutter pattern in order to estimate the efficacy of a therapy program. In addition, the applicability of the electrolaryngograph as a measurement tool for assessing and monitoring change in the vocal fold vibration of a stutterer is illustrated. Whereas traditionally, phonatory behaviours of stutterers were measured through the use of rating scales and other subjective means, the electrolaryngograph has been shown to be a useful and objective assessment tool for evaluating vocal fold behaviours.

\section{CONCLUSIONS AND IMPLICATIONS}

This study was directed to the objective evaluation of laryngeal behaviour pre- and post-intervention in an adult stutterer, the intervention being in the form of a fluency-based program designed to modify phonatory pattern and to reduce rate. The results revealed a marked difference between the laryngographic tracings in the two conditions. This difference was evident along several dimensions such as regularity, shape of the waveform, and ease with which steady amplitude is achieved, Gx and Fx. In addition to this, the results demonstrated a decrease in the frequency and severity of stuttering during reading, spentaneous speech and the telephone situation. A positive change in the subject's attitude was also noted.

Several clinical and theoretical implications are evident. These pertain not only to this particular subject or to stutterers in general, but also to the measurement techniques employed in this study! With regard to the subject of the present study, long-term followi up to assess the therapeutic gains is indicated and, indeed, the use of the electrolaryngograph to evaluate long-term outcome should prove informative. The utilization of the electrolaryngograph with other stutterers in an attempt to identify and describe the deviant phonatory pattern should prove interesting. Furthermore, the electrolaryngograph may be utilized in conjunction with techniques for the assessment of the respiratory and articulatory mechanism of the stutterer. Interactions between these systems have been reported (Adams 1974) and the evaluation of these should provide interesting information. Future research in these areas should contribute to the increasing amount of information in this field and consequently, therapeutic intervention should improve.

\section{ACKNOWLEDGEMENT}

The writer wishes to thank Professor A. Traill, Department of Linguistics, University of the Witwatersrand, Johannesburg, for his 
assistance in the administration and interpretation of the electrolaryngographic tracings.

\section{REFERENCES}

Adams, M.R. Vocal Tracts Dynamics in Fluency and Stuttering. In M. Webster and L. Furst (Eds.) Vocal Tract Dynamics and Dysfluency. Speech and Hearing Institute, New York, 1974.

Adams, M.R. and Reis, R. The Influence of the Onset of Phonation on the Frequency of Stuttering. J. Speech Hear. Res., 14, 639-644, 1971.

Andrews, G., Guitar, B., and Howie, P. Meta-analysis of the Effects of Stuttering Treatment. J. Speech Hear. Disord., 45, 287-307, 1981.

Andrews, G., Howie, P., Dosza, M. and Guitar, B. Stuttering: Speech Pattern Characteristics under Fluency Inducing Conditions. J. Speech. Hear. Res., 25, 208-216, 1982.

Andrews, G. and Ingham, R.J. Stuttering: Considerations in the Evaluation of Treatment. Brit. J. Commun. Disord., 6, 129-138, 1971.

Anthony, J. The Chief Scientist Reports ... the Voiscope. National Health Bulletin, London, 321-328, 1978.

Bloodstein, O. Stuttering as Tension and Fragmentation. In J. Eisenson (Ed.) Stuttering: A Second Symposium. Harper and Row, New York, 1975.

Boberg, E., Howie, P. and Woods, L. Maintenance of Fluency: A Review. J. Fluency Disord., 4, 93-116, 1979.

Conture, E.G., McCall, G.N. and Brewer, D.W. Laryngeal Behaviour During Stuttering. J. Speech Hear. Res. , 20, 661-668, 1977.

Cross, D. and Luper, H. Voice Reaction Times of Stuttering and Non-stuttering Children and Adults. J. Fluency Disord., 4, $59-78,1979$.
Erickson, R.L. Assessing Communication Attitudes among Stutterers. J. Speech Hear. Res., 12, 711-724, 1969.

Fourcin, A.J. and Abberton, E. First Applications of a New Laryngograph. Medical Biological llustrations, 21, 172-182, 1971.

Goldsmith, T. and Anderson, D. The Enigma of Fluency: a Single Case Study. S.A. J. Commun. Disord., 31, 47-52, 1984.

Gregory, H.H. Controversial Issues: Statement and Review of the Literature. In H.H. Gregory (Ed.) Controversies about Stuttering Therapy. University Park Press, Baltimore, 1979.

Hayhow, R. The Assessment of Stuttering and the Evaluation of Treatment. In P. Dalton (Ed.) Approaches to the Treatment of Stuttering. Croom-Helm, London, 1983.

Ingham, R.J., Andrews, G. and Winkler, R. Stuttering: A Comparative Evaluation of the Shorterm Effectiveness of Four Treatment Techniques. J. Commun. Disord., 5, 91-117, 1972.

Leith, W.R. and Timmons, J.L. The Stutterer's Reaction to the Telephone as a Speaking Situation. J. Fluency Disord., 8, 233-243, 1983.

Luper, H.L. and Mulder, R.L. Stuttering Therapy for Children Prentice Hall, Englewood Cliffs, 1964.

Metz, D.E., Onufrak, J.A. and Ogburn, R.S. An Acoustical Analysis of Stutterer's Speech Prior to and at Termination of Speech Therapy. J. Fluency Disord., 4, 249-254, 1979.

Perkins, W.H. Implicationsof Scientific Research for Treatment of Stuttering - a Lecture. J. Fluency Disord., 6, 155-162, 1981.

Schmitt, L.S. and Cooper, E. B. Fundamental Frequencies in Oral Reading Behaviour of Stuttering and Non-stuttering Male Children. J. Commun. Disord., 11, 17-23, 1978.

Schwartz, M.F. The Core of the Stuttering Block. J. Speech Hear. Disord., 39, 169-177, 1974.

Shames, G. and Florance, C.L. Stutter-Free Speech: A Goal for Therapy. Ohio: Charles E. Merrill, 1980.

Van Riper, C. Speech Correction: Principles and Methods. Prentice Hall, New Jersey, 1978.

Wingate, M.E. The Immediate Source of Stuttering: An Integration of Evidence. J. Commun. Disord., 10, 45-51, 1977. 


\title{
Hearing Aid Centre S.A. (Pty) Ltd
}

ESTABLISHED IN 1949

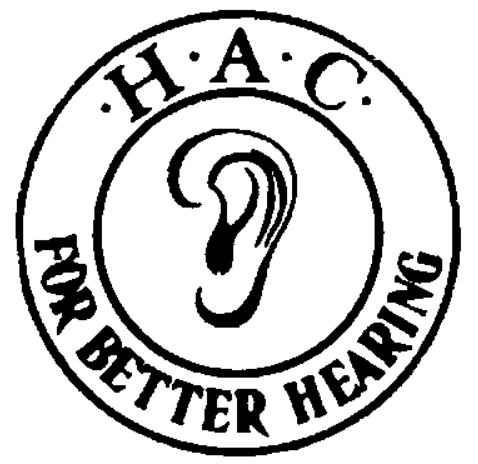

\section{Offers}

- Comprehensive wide range of modern hearing aids

- Complete service facilities

- Modern range of audiometric and allied equipment

- Own earmould laboratories

- In fact - everything that the audiologist may require

\author{
COUNTRY-WIDE SERVICE \\ AND FULLY EQUIPPED OFFICES AT \\ Johannesburg (Head Office) \\ Hearing Aid Centre S.A. (Pty) Ltd \\ 212 Harley Chambers \\ 187 Jeppe Street \\ JOHANNESBURG 2001 \\ Telephones: \\ $337-2643 / 4 / 5$
}

Pretorla

Hearing Aid Centre S.A. (Pty) Ltd 633 Kerkade Centre 267 Church Street PRETORIA 0002 Telephones:

\section{Cape Town}

Hearing Aid Centre S.A. (Pty) Ltd 104 Cartwright's Corner c/o Adderley \& Darling Streets CAPE TOWN 8001

21-7245/6 Telephone: 